\title{
Painéis fotográficos digitais: experiências de mostração em diário fotográfico na internet
}

Norberto Kuhn Júnior

\section{Resumo}

Propõe-se analisar o que denominamos usos do fotográfico por parte de sujeitos usuáriosprodutores nos ambientes midiáticos-digitais da rede mundial de computadores. Buscam-se os elementos de tecnicidade que são mobilizados nesses ambientes digitais, constitutivos do que denominamos painéis fotográficos digitais na internet e cuja marca principal é constituição de experiências de mostração fundadas em molduras visuais, geradas a partir da relação entre indivíduos, programas e aparelhos. Tais composições moldurais, de natureza infográfica (digital), são predominantemente visuais (podem incluir texto, áudio e vídeo), envolvendo os mais diversos conteúdos relativos à vida cotidiana. Foca-se, empiricamente, o caso do diário fotográfico UOL Fotoblog e das molduras visuais geradas no ambiente desse programa de serviço da empresa UOL.

\section{Palavras-chave}

Painéis fotográficos digitais. Fotoblogs. Internet.

\section{Norberto Kuhn Júnior | nkjunior@feevale.br}

Doutor em Ciências da Comunicação pela Universidade do Vale do Rio dos Sinos - UNISINOS. Professor do Centro Universitário Feevale.

\section{Introdução}

Neste artigo tratamos de caracterizar 0 que estamos denominando de painéis fotográficos na internet. Os Painéis são como aparelhos (FLUSSER, 2002) que viabilizam 0 compartilhamento de vivências pessoais na web através das mais diferentes composições visuais que, incorporadas às práticas cotidianas, passam a integrar o conjunto das ações humanas, compondo "ethicidades" (KILPP, 2003) digitais, ou seja, modos de ser que se realizam no mundo virtual da web. Os painéis fundam "experiências de mostração", e por "mostraçäo" estamos entendendo como a condição de disponibilidade técnica de fazer coisas e pessoas objetos do olhar, criando panoramas que agem sobre as relações sociais (BERGER, 1999). Tais "ethicidades" designam "subjetividades virtuais (as durações, as personas, objetos, fatos e acontecimentos) [...] [e] são construções midiáticas, cujos sentidos identitários (éticos e estéticos) são agenciados num mix de molduras e moldurações de imagens" (KILPP, 2003, p.33). 
Uma das principais marcas da tecnicidade conformadora desses Painéis é, como veremos, o seu modo de acionamento, que, em termos de produção e de uso, é predominantemente disparado por sujeitos individuais nos limites do que está programado pelos dispositivos técnicos (FLUSSER, 2002). Por tecnicidade não estamos tratando de aspectos puramente técnicos que estão no fundamento das aplicações digitais da fotografia na web; trata-se de entender a técnica como uma dimensão constitutiva dos modos de ser no mundo, aos quais determinados usos sociais estão associados.

Uma vez que os usuários provocam a sua imersão na tela do computador - e se deparam com painéis visuais, imagens dentro de imagens - define-se, ao nosso ver, um "mundo de experiências" em que a ação sígnica se produz e se reproduz nos usos possíveis que os indivíduos fazem da fotografia que atuou naquele ambiente virtual. Esse "mundo de experiências" constitui-se de uma sobreposição de molduras (KILPP, 2003).

Quais são os elementos de tecnicidade que são mobilizados nesses ambientes digitais e como tais tecnicidades resultam em experimentos de mostração - jogos produtores de realidade magicizada - em que as experiências particulares, as subjetividades, assumem a forma de acontecimento midiático? Para dar conta dessa questão, privilegiaremos neste artigo sujeitos e suas experiências de mostração expressos em produtos fotográficos e usos fotográficos nos ambientes digitais do serviço de diário fotográfico do portal de conteúdos e provedor de internet Universo Online, o UOL Fotoblog. Partindo da problemática proposta, conduziremos o estudo do UOL Fotoblog considerando-o sob dois níveis de análise:

a) Apresentamos a construção da noção de painéis fotográficos digitais, a partir da qual demarcamos teoricamente o objeto de estudo UOL Fotoblog e apresentamos os conceitos operacionalizadores da sua análise: moldura e moldurações, aparelho e programa;

b) 0 segundo nível de análise é composto pelo desenvolvimento da descrição da composição da tecnicidade dos painéis, com base na sua análise moldural subdividida em: detalhamento das estruturas macromoldurais (constitutivas do portal de conteúdos e provedor de internet Universo Online) e detalhamento da moldura de serviço de diário fotográfico UOL Fotoblog; e os desdobramentos empíricos da tecnicidade painéis em acontecimentos fotográfico-digitais; aqui analisamos as propriedades dos programas de mostração específicos do UOL Fotoblog onde estão implicados processos de molduração que denominamos de molduras internas de mostração. 


\section{A construção da noção de painéis fotográficos digitais}

Tomamos como ponto de partir a noção de molduras visuais de Susana Kilpp (2003), o que nos permite considerar os fotoblogs como uma tecnicidade capaz de fundar experiências de mostração como acontecimento (CHARAUDEAU, 2006).

Moldura se define pela capacidade de instituir, sobre as paisagens, limiares significativos, ou seja, partes dotadas de sentidos éticos e estéticos, sendo essa capacidade relativa às historicidades dos sujeitos (experiências dos sujeitos socioculturalmente constituídos). Partindo desse conceito geral, entendemos por moldura toda e qualquer forma/conteúdo sígnico (visual ou audiovisual) que se realiza na capacidade ou na força de demarcação de espaços ou circunstâncias de realização de conteúdos significativos; por molduração, entendemos o exercício (intencionalidades) dessa capacidade de produzir e promover signos de contenção de signos.

Trazida para nosso contexto de análise, moldura é um demarcador de ambiências de significação cuja materialidade infográfica assume variadas formas, texturas, volumes, cores, movimentos, sonoridades. Por meio dessas materialidades infográficas são enunciados sentidos que, por sua vez, são agenciados no interior de processos digitais de produção e de recepção - processos de construção intelectual para se fazer visto e construir um ponto de vista. No caso do UOL
Fotoblog, entendido como um programa de serviço emoldurado pela empresa midiática UOL, temos uma ambiência de significação em que operam forças de demarcação de conteúdos significativos que entendemos como dinamizadoras de uma "ethicidade" específica. Tal "ethicidade" se faz visível, se realiza mediante paisagens que emergem na tela do computador, uma coleção de imagens fotográficas digitais (ou infográficas) constituída a partir de múltiplos acionamentos moldurais sobrepostos, que estamos denominando de painéis fotográficos digitais.

Para tratar sobre como as experiências cotidianas vão sendo fotograficamente emolduradas em painéis, tomamos como ponto de partida as noções de aparelho e programa, segundo Flusser (2002). Considerado por Flusser 0 modelo para todos os aparelhos da atualidade, o aparelho fotográfico exerce a atividade de produzir, armazenar e manipular os símbolos. 0 que caracteriza 0 aparelho é 0 fato de estar programado, e as fotografias são realizações de algumas das potencialidades inscritas nele. 0 fotógrafo é o funcionário que não apenas joga com o aparelho, mas contra ele, procurando esgotar o programa nele inscrito. Para Flusser (2002), o sujeito encontra-se dentro do aparelho: sujeito e aparelho se confundem.

0 aparelho fotográfico está programado para produzir fotos automaticamente - segundo 0 que está programado em sua dimensão física 
(dura - hardware, equivalente ao dispositivo)

-, ao mesmo tempo em que é programado

para permitir que o fotógrafo faça fotografias

- o programado em sua dimensão simbólica, interpretativo-criativa, resultado da imaginação do fotógrafo (mole - software). Assim, desde 0 hardware, ele emancipa o fotógrafo do trabalho e 0 libera para 0 jogo. 0 aspecto instrumental dá lugar ao aspecto "brinquedo", ao jogo criativo. Dito de outro modo, o fotógrafo faz funcionar 0 aparelho (hardware) segundo seu programa"Funcionar é permutar símbolos programados" (FLUSSER, 2002, p. 25) -, e nessa operação instrumental liberta-se para o jogo (software) onde pode realizar-se como sujeito criativo.

Tomamos os painéis em sua constituição técnica (moldural), como mimese do gesto fotográfico de que nos fala Flusser (2002): ao portal provedor de internet, como uma "fábrica" no sistema industrial midiático, corresponde a dimensão estrutural do aparelho; este constitui-se, desde fora, por metaprogramas (macromolduras, relativas aos negócios dessa indústria midiática), que programam outros programas que se realizam como produto em forma de serviços, que denominamos de programa de serviço. Assim, nos direcionamos para 0 interior de distintos níveis moldurais que fazem conter os interesses da fábrica (replicam programáveis). Um desses programáveis é o programa de serviço fotográfico que, no ambiente da "fábrica" UOL, denomina-se UOL Fotoblog.

Daí o nascimento do termo aparelho-provedor, para se referir ao portal-provedor de internet UOL, do termo programa de serviço, para se referir ao serviço UOL Fotoblog, e do termo usuário-produtor para se referir à dupla função dos sujeitos nas relações desenvolvidas no processo de molduração dos painéis (sistematizados no Quadro 1).

Quadro 1: Termos analisadores e seus objetos correspondentes

\begin{tabular}{|c|c|}
\hline Termo analisador & Objeto \\
\hline Aparelho-provedor & Portal de conteúdo e provedor de acesso à internet - Universo On Line \\
\hline Programa de serviço & Serviço de diário fotográfico - UOL Fotoblog \\
\hline Usuário-produtor & Sujeitos que operam o serviço de diário \\
\hline
\end{tabular}


Assim, no ambiente desses programas de serviço que são os fotoblogs, o usuário vai sobrepondo molduras fotográficas, compondo e recompondo temporalidades visuais e atualizando experiências de interação a partir das imagens acessadas. Há, portanto, sujeitos jogando com aparelhos. Nesse caso, 0 aparelho é o UOL, que fornece tecnicamente as condições de acesso ao fotoblog; trata-se de um sujeito jurídico empresarial, inscrito na lógica da produção de bens midiáticos e orientado por determinações de ordem mercantil.

Mas há, igualmente, milhares de sujeitos individuais que se aliam dialogicamente ao aparelho. E, ao fazê-lo, lançam-se para o seu interior e constituem-se não apenas como usuários-consumidores de um programa de serviço, mas atuam como seus próprios produtores, ou seja, desde 0 interior dos painéis operam, por meio dos usos, a sua própria constituição, seja compondo seu próprio jogo de molduras (o seu fotoblog), seja compondo sobre as que estão aí disponibilizadas (interagindo com outros fotoblogs). Desse modo, esses sujeitos usuários e produtores podem estar recompondo sua própria subjetividade, sendo essas condições técnicas de mostração, como "ethicidade", a sua própria condição de realização (BRUNO, 2005; SANZ, 2005).

Analisamos agora como se reproduzem essas redes de significação que transformam a ação do próprio provedor em acontecimento-produto.

\section{A tecnicidade dos painéis: 0 aparelho-provedor UOL e sua moldura-de-serviço UOL Fotoblog}

Os painéis são produtos e estão associados a macromolduras comerciais que os colocam em circuitos comunicacionais e garantem sua realização na medida mesma em que estes realizam o negócio de aparelho-provedor (0 consumo, pelo uso, dos seus programas de serviço), segundo os metaprogramas de um capitalismo informacional (CASTELLS, 1999).

Entendemos os fotoblogs como um produto dessas empresas tecnoinformacionais, cuja materialidade visual está determinada pela relação entre distintos níveis moldurais. Quanto ao processo de emolduramento configurador da tecnicidade dos painéis fotográficos digitais, consideramos duas dimensões sobrepostas: as dimensões macromoldurais (empresa UOL, Figura 1) e as dimensões moldurais do próprio programa de serviço UOL Fotoblog (Figura 2). Ao nos direcionarmos para o interior dessas dimensões moldurais, poderemos identificar as intenções do aparelho inscritas nos seus modos de operar a programação dos seus serviços.

Figura 1: Ícone do UOL, versão 2008

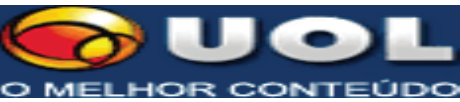

Fonte: UOL site, http://www.uol.com.br

Figura 2: Moldura de serviço UOL Fotoblog

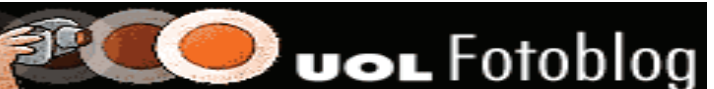

Fonte: UOL Fotoblog, http://fotoblog.uol.com.br 
Foi a partir de 2004 que os chamados "diários pessoais" passaram a figurar entre os programas de serviço oferecidos no UOL. Os blogs estrearam, seguidos do fotoblogs e dos serviços do álbum de fotos para produtores-usuários assinantes. Já a partir de 2005 os fotoblogs ficaram acessíveis também aos produtores-usuários visitantes. Ainda em 2005, passaram a ser integrados à telefonia celular, por meio da qual podem ser atualizados. Os blogs e os fotoblogs também foram integrados aos serviços de correio eletrônico e de comunicação instantânea do UOL Webmail; assim, fotografias, textos, mensagens, conversação instantânea (batepapo), passaram a ser integrados à telefonia celular (SOBRE UOL). Dito de outro modo, os painéis são emoldurados como produto de mercado informacional, cuja realidade depende da realização de experimentos visuais em redes de relações fundadas em usos individuais.

O usuário-produtor assinante ou visitante é quem faz a ativação das operações de acesso, visualização e desenvolvimento dos diferentes programas de serviços disponíveis nas diferentes dimensões moldurais constitutivas do próprio aparelho-provedor. 0 usuário-produtor dispara ações de produção e consumo, mas sempre nos limites dos programas emoldurados e molduradores do aparelho-provedor UOL e 0 seu programa UOL Fotoblog.

0 que permite transcender a esfera das redes de relações fundadas em usos individuais transformando os painéis em um componente de realização do próprio aparelho e seus programas de serviço é a emolduração do "acesso" à mostração (de visualidade).

As motivações de acesso e interação por meio das quais o usuário vai acionar e interromper fluxos de visualização (assim é que se produz o produto "acesso à visualidade") estão programadas pelo aparelho-provedor UOL, no âmbito dos serviços que emolduram um uso (programa de serviço). No caso do UOL Fotoblog, são variadas as molduras de acesso: acesso motivado por publicização ("fotoblogs legais", "fotoblog especial", "fotoblogs legais - destaque do público", "ranking"); acesso por meio de ferramentas de busca; acesso motivado por publicização e sobreposição de molduras "fotoblogs comunitários" e outros programas de serviços constitutivos da macromoldura UOL (UOL Blog, UOL Sites, UOL Álbum de fotos, Videolog).

Temos que o produto fundamental dos processos de emolduramento, definidos no âmbito dessas molduras de acesso e visualidade dos fotoblogs, é o próprio acesso à visibilidade: todos os mecanismos do programa de serviço (ferramentas de desenvolvimento e configuração) disponibilizados pelo aparelho-provedor estão orientados a aumentar a capacidade de visitação aos fotoblogs. A visibilidade dos experimentos dos usuários-produtores depende dessa capacidade de mostração, tanto quanto dela depende o próprio aparelho-provedor e os patrocinadores do serviço. 
Dito de outro modo, aliada à capacidade de os usuários-produtores ampliarem a visibilidade dos seus materiais está a capacidade de publicizar não apenas fotos particulares, mas, principalmente, componentes macromoldurais: a divulgação de um fotoblog (ou de uma única foto) é igualmente a publicização dos programas de serviço da macromoldura (produtos e serviços gratuitos ou pagos), bem como das suas disponibilidades técnicas. Uma vez ampliadas as chances de divulgação de um programa de serviço específico, tem-se igualmente ampliado o alcance de visibilidade e acesso às macromolduras patrocinadoras (links patrocinados). Por isso a importância de fazer chegar aos usuários dos fotoblogs os modos e as estratégias de divulgação dos seus materiais, preconfigurando ao máximo essas disponibilidades técnicas, bem como fortalecendo 0 valor das capacidades de tornar visíveis os materiais fotográficos ("Divulgue suas fotografias!").

Estamos vendo que a relação entre os sujeitos usuários-produtores e os aparelhos está contida nas molduras do programa de serviço dos painéis; estes visam fundamentalmente assegurar a reprodução do seu uso como produto midiático-digital, gerando condições técnicas e competências capazes de criar, armazenar e atualizar - inserindo/apagando - as imagens fotográficas que lhes são constitutivas.

Nesses termos é que associamos a reprodutibilidade de um painel à sua capacidade de atualizar-se: a reprodutibilidade desse produto, que é o seu uso pela mostração e visualização (sua visualidade), está associada às condições de atualização (continuidade e permanência) e circulação (novos acessos) das imagens colocadas à mostra. Essa atualização se dá tanto por intensificação da densidade de mostração, o que significa somar novas imagens às já existentes, quanto pela operação de substituição - deletabilidade - das imagens antigas e inclusão de novas. De qualquer modo, quanto mais o processo de atualização incidir sobre 0 aumento da densidade de mostração (e não resultar apenas de substituição de antigas imagens por novas), maiores as chances de reprodutibilidade dos painéis.

Nessa perspectiva, assume importância a capacidade de transformar as produções visuais particulares em acontecimento e de aportá-las às redes comunitárias e circuitos de amizade. No final do ano de 2005, o UOL K estreou como uma rede de relacionamento gratuita integrando vários serviços (blog, videoblog, chat, e-mail, telefonia celular). Em 2006, a empresa lançou o UOL Fone, aberto a qualquer internauta. $\mathrm{Na}$ rede de relacionamento UOL K, os internautas cadastrados no bate-papo ganharam perfil com foto, e os fotoblogs podem receber até quatro mil fotos. Daí o porquê de considerarmos produto não apenas as imagens partilhadas, mas a capacidade de torná-las visíveis, tanto quanto as macromolduras que as sustentam, para o maior número possível de pessoas. 
Porém, a reprodutibilidade desse produto

- que, como dissemos, é o próprio uso na mostração - está igualmente associada às condições de vinculação e aos denominados circuitos de confiança. Atualizando a noção de confiança em sistemas abstratos (GIDDENS, 1991), referimo-nos, aqui, especificamente aos mecanismos que viabilizam acionamento de acesso direto a outros fotoblogs selecionados pelo usuário e emoldurados no UOL Fotoblog como "fotoblogs favoritos" e acesso a redes de recomendação de fotoblogs com experiências afins (moldura "recomendo"). Esses mecanismos são gerenciáveis no âmbito das molduras de configuração dos fotoblogs e estão ligados à publicização dos programas de serviço da macromoldura (produtos e serviços gratuitos ou pagos) - podem ou não ser acionados pelo usuário-produtor. Tais circuitos instauram processos de autorreferencialidade, vitais para 0 funcionamento da macromoldura.

Os processos interacionais demandam, nesse caso, a configuração de circuitos de confiança. As noções de comunidade e amizade reincidentes na enunciação dos produtos e serviços do aparelhoprovedor não são apenas algo a mais, simples qualificadores dos processos interacionais instaurados pelo partilhamento visual (do que se leva à mostra). Elas efetivamente fundam a própria condição de ser do programa de serviço ofertado pela empresa; ou seja, ligado a essa sua qualificação está 0 "acesso à visibilidade" como condição constitutiva do próprio ambiente de consumo, o que depende da operação simbólica das noções de "amizade", "comunidade", "permissão" e "convite". Expressões como "agora é só mostrar para os amigos" ou "envie para um amigo" apontam para a centralidade desses circuitos de confiança (pautados na noção de amizade) na constituição do programa de serviço ofertado pelo aparelho-provedor (o que se faz possível justamente nos limites programados dessa macromoldura que é, nesse caso, 0 provedor UOL).

0 que nos importou até aqui foi perceber o quanto esses mecanismos abrem possibilidades para a composição de redes moldurais que, tecnicamente, se compõem e recompõem de modo inesgotável. $\mathrm{E}$, mesmo que esses painéis corram o risco de esvaziamento de sentido - pois na complexidade da rede podem assumir 0 sentido de "sempre ser a mesma coisa" (BRUNO, 2005) ou, ainda, de nada representar (nem experiências vividas, nem qualidades partilhadas, nem competência fotográfica reconhecida) -, essa mesma rede compõe o programa de serviço que faz os painéis fotográficos pessoais se converterem em um extenso banco de imagens e subjetividades de propriedade legal do aparelho-provedor, que fornece aos usuários-produtores as condições técnicas de realização visual das suas subjetividades.

\section{As propriedades dos programas de mostração específicos do UOL Fotoblog}

Partilhando do entendimento de Sanz (2005)

e Bruno $(2004 ; 2005)$, não se fotografa 0 
acontecimento, se faz acontecimento por ser fotografado. Adequando esse entendimento ao objeto deste estudo, poderíamos complementar dizendo que se faz acontecimento por ser emoldurado digitalmente. Esse é 0 caso dos "painéis" fotográficos. Eles se realizam em emolduramentos midiáticos, e sob essa condição realizam 0 acontecimento, onde jogam tanto as intencionalidades subjetivas (de exteriorização das intimidades), quanto as objetividades programadas nos aparelhos, ou seja, constituem-se os "painéis" fotográficos como ambientação midiática, segundo critérios próprios de um aparelho-provedor e de seus programas de serviço.

A partir do interior dos painéis (esses que se realizam por meio de operações sígnicas da ordem do pós-fotográfico, implicados por processos de virtualização), instauram-se experiências de mostração mediante o partilhamento de múltiplas composições fotográficas e seus componentes textuais. Tais composições resultam dos processos de molduração que denominamos de molduras internas de mostração. Nesse âmbito estão, sujeitos e aparelho, em situação de jogo (FLUSSER, 2002), tensionando agendas temáticas individuais e agendas operadas midiaticamente, ou seja, usos individuais associam-se às operações geradas pelo aparelhoprovedor, e, desde aí, dispara-se o processo de emolduração de acontecimentos.

Uma modalidade típica de acontecimento organizado por meio dos painéis pode ser observada naqueles casos em que a força sígnica das coleções de fotografias e imagens digitais instaura molduras documentais e memórias de grupos e/ou indivíduos; tais casos demarcam experiências de interações na medida em que os conteúdos apresentados nas fotografias são significados pelo olhar de quem, direta ou indiretamente, está implicado na própria condição da experiência vivida junto aos referentes. As imagens - poses com amigos, familiares, animais, objetos, ou mesmo autorretratos, em circunstâncias de uma visita a um familiar, o nascimento de um bebê, um jantar entre amigos - indicam experiências partilhadas no próprio gesto fotográfico, em que fotógrafo e fotografado participam diretamente das circunstâncias de tempo/espaço retidas na imagem. As interações, nesses casos, dependem da força de ação das imagens em nos lançar para exercício perceptivo e interpretativo das experiências vividas entre fotógrafo e fotografado, portanto está fortemente ligada à mobilização dos indicativos dessas experiências.

Há casos em que as agendas midiáticas se associam às individuais. Esses, muito embora sejam pouco representativos no contexto temático dos painéis, recebem o destaque de "fotoblogs especiais". Os "fotoblogs especiais" são definidos pela relação que os usuáriosprodutores dos painéis estabelecem com acontecimentos midiáticos que integram as agendas macromoldurais (por exemplo, jornais e notícias online), e que se constituem como tal 
no âmbito dessas dimensões macromoldurais.

No entanto, para esses casos, desenvolve-se uma moldura específica, e os usuários-produtores são orientados a enviar suas fotos para compor um painel especial com um endereço eletrônico específico. Como exemplo de um painel fotográfico, composto a partir da interação direta entre aparelho-provedor (seus peritos) com usuários-produtores de fotoblogs, podemos tomar o caso dos Jogos Pan-Americanos (ver Figura 3), composto por fotos enviadas ao UOL Fotoblog pelo e-mail vocenopan@uol.com.br. Como exemplo, temos 0 caso de F.C. (Rio de Janeiro - RJ), em que aparecem "Minha mãe com 0 campeão panamericano de caratê Juarez Santos. Valeu, Brasil!".

Figura 3: Moldura do fotoblog "Jogos Pan Americanos"

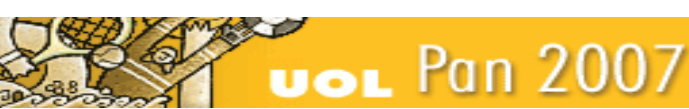

Fonte: UOL fotoblog, http://vocenopan.nafoto.net

Outro exemplo é o caso do Fotoblog Especial "Seu Réveillon 2008" (Figura 4), em que aparece a chamada do UOL Fotoblog: "Este é um fotoblog feito com fotos tiradas e enviadas pelo internauta e publicadas pelo UOL Fotoblog. Mande apenas fotos tiradas por você mesmo(a). Vale tudo o que for relacionado a Réveillon: fotos da festa, de viagem, da ceia, de amigos ou família comemorando, etc." (UOL Fotoblog, http://seureveillon.nafoto.net).

Pelo link http://seureveillon.nafoto.net/ photo20080104161617.html é possível acessar fotos como "As donas da casa", enviadas por M. D. M (São José do Rio Pardo -SP)

Figura 4: Moldura do fotoblog "Seu Réveillon"

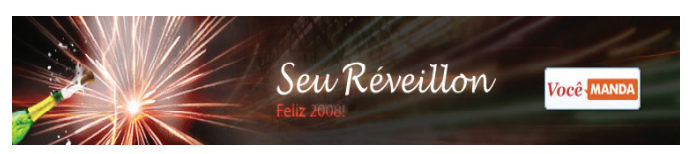

Fonte: UOL fotoblog, http://seureveillon.nafoto.net

Nesses dois casos, vemos um painel fotográfico digital sendo composto pelo partilhamento de experiências dos referentes (foco da imagem na experiência partilhada), em que o processo de emolduração do acontecimento se dá por orientação temática explícita de programa de serviço e do aparelho-provedor. 0 que vale para os sujeitos em interação nos painéis é a indicialidade da experiência ${ }^{1}$.

\section{Painéis fotográficos digitais: a mostração de experiências individuais $\mathrm{e} 0$ aparelho-provedor como acontecimento midiático}

Voltamos agora para a questão inicial: o que nos permite afirmar que tais painéis fotográficos digitais resultam em experimentos de mostração em que as experiências particulares, as subjetividades, são magicizadas como acontecimento midiático?

Em nosso entender, o que responde a essa pergunta não é apenas o fato de tais experiências estarem aportadas em aparelhos e programas midiáticos que operam na sua molduração, 
compondo redes de significação associadas estritamente às criações de um usuárioprodutor individual. É o fato de, por meio dessas mesmas moldurações, no partilhamento visual de experiências individuais, estarem colocadas as condições de reprodução de redes de significação que transcendem a esfera das relações fundadas em usos individuais, e que se transformam em um componente de realização do próprio aparelho e seus programas de serviço. Ou seja, a mostração de experiências individuais transforma em acontecimento a ação do próprio aparelho-provedor: o que é levado à condição de objeto do olhar é o serviço do provedor, que se realiza, portanto, no jogo sincrônico das objetividades programadas nos aparelhos e das intencionalidades subjetivas dos usuários-produtores. 0 produto desse jogo é a visualidade no âmbito dos painéis: 0 seu acontecimento é dado na mesma operação que tanto realiza as experiências visuais dos usuários-produtores quanto realiza o aparelho que nelas se reproduz.

Todas as ações do aparelho, seus investimentos, produtos e serviços desenvolvidos - enfim, os seus programáveis - estão voltados a sua reprodução como empresa no mercado tecnológico e comunicacional. Implicadas aí estão as relações de produção e consumo de bens simbólicos (relação entre produtores e consumidores), cujas práticas concretas de venda, publicidade e marketing cada vez mais ajustam reciprocamente, em molduras únicas, mercado e ambiente de sites e provedores de internet (MONTARD0, 2005).

Por isso, também, destacamos, na composição macromoldural do UOL como aparelho-provedor de internet, aqueles componentes que marcam a reprodução do UOL como negócio: seus ícones identitários, aos quais associa seus parceiros comerciais por meio de links patrocinados.

Tais ícones demarcam (emolduram), por automatismos programados no aparelho, todos os seus ambientes, produtos e serviços.

Temos então que a mostração, como um produto específico para consumo de usuários individuais (derivado dos acionamentos de um programa de serviço específico), é também condição de sua realização em âmbitos macromoldurais, a partir da relação entre usuário-produtor, provedor e parceiros comerciais. Ou seja, cada fotoblog desenvolvido significa para o provedor a sua própria realização: amplia a capacidade de circulação de vários outros de seus programas de serviço, à medida que estes são acionados pelo próprio usuário-produtor no momento em que cria, desenvolve e põe em circulação seu fotoblog.

Nessa perspectiva, assume importância a capacidade de transformar as produções visuais particulares em acontecimento, de fazê-las circular e de aportá-las às redes comunitárias e aos circuitos de amizade, capazes de estender, ao máximo, 0 alcance das macromolduras comerciais. Desse modo, a partir do interior dos fotoblogs, instauram-se experiências de 
visibilidade, experiências de mostração por meio do partilhamento de múltiplas composições fotográficas e de seus componentes textuais.

Entre os aspectos de tecnicidade dos painéis que nos chamaram atenção, está 0 emolduramento dos mecanismos de circulação das coleções privadas de fotografias e imagens digitais, que, na mesma medida em que geram experiências de interação baseadas no acontecimento da mostração, potencializam, a cada imagem disponibilizada para acess 0, a circulação dos componentes macromoldurais (ícones do provedor e de seus serviços, links patrocinados) que estão na base das condições de existir do aparelho-provedor. 0 produto é a mostração privada magicizada, pelos emolduramentos, em acontecimento. 0 produto é tanto 0 acontecimento individual (privado) da experiência de interação quanto sua capacidade de fazer acontecer a realidade do próprio aparelho - daí a constituição de uma "ethicidade" digital (nesse caso, expressa pelo fenômeno digital dos fotoblogs - um entre tantos outros).

Quanto a essa transformação do aparelhoprovedor que acontece como produto, ela tem sua gênese dependente tanto da ação indireta dos componentes macromoldurais quanto da ação direta dos componentes de acesso e desenvolvimento, próprios de um programa de serviço. Porém, sua principal fonte geradora reside nos experimentos de interação, emoldurados no âmbito das dimensões internas dos painéis digitais, no compartilhamento direto de fotografias e imagens e na relação que se estabelece entre os sujeitos individuais na mostração.

\section{Referências}

BERGER, John. Modos de ver. Rio de Janeiro: Rocco, 1999.

BRUNO, Fernanda. Máquinas de ver, modos de ser: visibilidade e subjetividade nas novas tecnologias de informação e de comunicação. In: ENCONTRO ANUAL DA ASSOCIAÇÃO DOS PROGRAMAS DE PÓS-GRADUAÇÃO ME COMUNICAÇÃO, 13., 2004, São Paulo. Anais... São Paulo: Compós, 2004. CD-R0M. BRUNO, Fernanda. Quem está olhando? Variações do público e do privado em weblogs, fotologs e reality shows. Contemporânea, Salvador, v. 3, n. 2, p. 53-70, jul.-dez. 2005.

CASTELLS, Manuel. A sociedade em rede. São Paulo: Paz e Terra, 1999.

CHARAUDEAU, Patrick. Discurso das mídias. São Paulo: Contexto, 2006. 285 p.

FLUSSER, Vilém. A filosofia da caixa preta: ensaios para uma futura filosofia da fotografia. Rio de Janeiro: Relume Dumará, 2002.

GIDDENS, Anthony. As conseqüências da modernidade. 2.ed. São Paulo: Unesp, 1991.

KILPP, Suzana. Ethicidades televisivas. São Leopoldo: Unisinos, 2003.

\section{KUHN JÚNIOR, Norberto. Painéis fotográficos na}

internet: um estudo sobre os fotoblogs como molduras de mostração. 2008. 174 f. Tese (Doutorado em Ciências da Comunicação)- Universidade do Vale do Rio dos Sinos, São Leopoldo, 2008.

MONTARD0, Sandra Portella. Comunicação e cibercultura: a forma social na tragédia da cultura. 
Revista Famecos, Mídia, Cultura e Tecnologia, Porto Alegre, n.26 , p.139-140, abr. 2005.

SANTAELLA, Lucia. Culturas e artes do pós-humano: da cultura das mídias à cibercultura. São Paulo: Paulus, 2003. 359 p.

SANZ, Claudia Linhares. Passageiros do tempo e a experiência fotográfica: do álbum de família ao blog digital. Disponível em: <www.studium.iar.unicamp. br/22/alb_blog/index.html>. Acesso em: 15 dez. 2005.

SOBRE UOL. Link de serviço de atendimento ao consumido do portal de conteúdos e provedor de internet UOL. Disponível em: <http://sobre.uol.com.br/ historia/audiencia.jhtm>. Acesso em: 27 jul. 2007.

UNIVERSO ON LINE. Portal de conteúdos e provedor de internet. Disponível em: <http://www.uol.com.br/>. UOL FOTOBLOG. Serviço de diário fotográfico do portal de conteúdos e provedor de internet UOL. Disponível em: <http://fotoblog.uol.com.br/>. 


\section{Digital photography panels: visual experiences generated in photo diaries on the Web}

\section{Abstract}

In this paper we are proposing the analysis of what we are calling the "photographic uses" by both users and producers in the digital-midiatic environment on the Web. We sought the technical elements that are mobilized in this digital environment and that are made of what we are calling digital photography panels on the Internet, which principal characteristic is the constitution of visual experiences funded on visual frames generated by the relation between individuals, programs and devices. These framing compositions of (digital) infographic nature are mainly visual (they may use text, audio and video) involving diverse contents related to everyday life. We focus, empirically, on the UOL Fotoblog case and the visual frames generated in the environment of this UOL service program.

\section{Keywords}

Digital photography panels. Fotoblogs. Internet.

\section{Paneles fotográficos digitales: experiencias de visualización en diario fotográfico en Internet}

\section{Resumen}

Se propone analizar lo que denominamos usos de lo fotográfico por parte de sujetos usuariosproductores en los ambientes mediáticos-digitales de la red mundial de computadores. Se buscan los elementos de tecnicidad que son movilizados en esos ambientes digitales, constitutivos de lo que denominamos paneles fotográficos digitales en Internet y cuya marca principal es la constitución de experiencias de visualidad fundadas en marcos visuales, generados a partir de la relación entre individuos, programas y aparatos. Tales composiciones en los marcos, de naturaleza infográfica (digital), son predominantemente visuales (pueden incluir texto, audio y vídeo), envolviendo los más diversos contenidos relativos a la vida cotidiana. Se enfoca, empíricamente, el caso del diario fotográfico UOL Fotoblog y de los marcos visuales generados en el ambiente de ese programa de servicio de la empresa UOL.

\section{Palabras clave}

Paneles fotográficos digitales. Fotoblogs. Internet. 


\section{Expediente}

A revista E-Compós é a publicação científica em formato eletrônico da Associação Nacional dos Programas de Pós-Graduação em Comunicação (Compós). Lançada em 2004, tem como principal finalidade difundir a produção acadêmica de pesquisadores da área de Comunicação, inseridos em instituições do Brasil e do exterior.
E-COMPÓS I www.e-compos.org.br I E-ISSN 1808-2599

Revista da Associação Nacional dos Programas de Pós-Graduação em Comunicação. Brasília, v.12, n.1, jan./abr. 2009.

A identificação das edições, a partir de 2008 passa a ser volume anual com três números.

\section{CONSELHO EDITORIAL}

\section{Afonso Albuquerque}

Universidade Federal Fluminense, Brasil

Alberto Carlos Augusto Klein

Universidade Estadual de Londrina, Brasi

Alex Fernando Teixeira Primo

Universidade Federal do Rio Grande do Sul, Brasil

\section{Alfredo Vizeu}

Universidade Federal de Pernambuco, Brasil

Ana Carolina Damboriarena Escosteguy

Pontifícia Universidade Católica do Rio Grande do Sul, Bras

Ana Silvia Lopes Davi Médola

Universidade Estadual Paulista, Brasil

André Luiz Martins Lemos

Universidade Federal da Bahia, Brasil

Ângela Freire Prysthon

Universidade Federal de Pernambuco, Brasil

Antônio Fausto Neto

Universidade do Vale do Rio dos Sinos, Brasil

Antonio Carlos Hohlfeldt

Pontifícia Universidade Católica do Rio Grande do Sul, Brasil

Arlindo Ribeiro Machado

Universidade de São Paulo, Brasil

César Geraldo Guimarães

Universidade Federal de Minas Gerais, Brasil

Cristiane Freitas Gutfreind

Pontifícia Universidade Católica do Rio Grande do Sul, Brasil

Denilson Lopes

Universidade Federal do Rio de Janeiro, Brasil

Eduardo Peñuela Cañizal

Universidade Paulista, Brasi

Erick Felinto de Oliveira

Universidade do Estado do Rio de Janeiro, Brasil

Francisco Menezes Martins

Universidade Tuiuti do Paraná, Brasil

Gelson Santana

Universidade Anhembi/Morumbi, Brasi

Hector Ospina

Universidad de Manizales, Colômbia

leda Tucherman

Universidade Federal do Rio de Janeiro, Brasil

Itania Maria Mota Gomes

Universidade Federal da Bahia, Brasil

Janice Caiafa

Universidade Federal do Rio de Janeiro, Brasil

Jeder Silveira Janotti Junior

Universidade Federal da Bahia, Brasil

\section{João Freire Filho}

Universidade Federal do Rio de Janeiro, Brasil

John DH Downing

University of Texas at Austin, Estados Unidos

José Luiz Aidar Prado

Pontifícia Universidade Católica de São Paulo, Brasil

José Luiz Warren Jardim Gomes Braga

Universidade do Vale do Rio dos Sinos, Brasil

Juremir Machado da Silva

Pontifícia Universidade Católica do Rio Grande do Sul, Brasil

Lorraine Leu

University of Bristol, Grã-Bretanha

Luiz Claudio Martino

Universidade de Brasília, Brasil

Maria Immacolata Vassallo de Lopes

Universidade de São Paulo, Brasil

Maria Lucia Santaella

Pontifícia Universidade Católica de São Paulo, Brasil

Mauro Pereira Porto

Tulane University, Estados Unidos

Muniz Sodre de Araujo Cabral

Universidade Federal do Rio de Janeiro, Brasil

Nilda Aparecida Jacks

Universidade Federal do Rio Grande do Sul, Brasil

Paulo Roberto Gibaldi Vaz

Universidade Federal do Rio de Janeiro, Brasil

Renato Cordeiro Gomes

Pontifícia Universidade Católica do Rio de Janeiro, Brasil

Ronaldo George Hela

Universidade do Estado do Rio de Janeiro, Brasil

Rosana de Lima Soares

Universidade de São Paulo, Brasil

Rossana Reguillo

Instituto Tecnológico y de Estudios Superiores do Occidente, México

Rousiley Celi Moreira Maia

Universidade Federal de Minas Gerais, Brasil

Sebastião Carlos de Morais Squirra

Universidade Metodista de São Paulo, Brasi

Simone Maria Andrade Pereira de Sá

Universidade Federal Fluminense, Brasil

Suzete Venturelli

Universidade de Brasília, Brasil

Valério Cruz Brittos

Universidade do Vale do Rio dos Sinos, Brasil

Veneza Mayora Ronsini

Universidade Federal de Santa Maria, Brasil

Vera Regina Veiga França

Universidade Federal de Minas Gerais, Brasil
COMISSÃO EDITORIAL

Ana Gruszynski I Universidade Federal do Rio Grande do Sul, Brasil

Rose Melo Rocha I Escola Superior de Propaganda e Marketing, Brasil

CONSULTORES AD HOC

Alberto Schneider I Visitante Tokyo University

Alexandre Rocha da Silva I Universidade Federal do Rio Grande do Sul, Brasil

Fernanda Bruno I Universidade Federal do Rio de Janeiro, Brasil

Ida Stumpf I Universidade Federal do Rio Grande do Sul, Brasil

Kati Caetano I Universidade Tuiuti do Paraná, Brasil

Laura Cánepa I Universidade Anhembi Morumbi, Brasi

Malena Contrera I Universidade Paulista, Brasil

Sandra Gonçalves I Universidade Federal do Rio Grande do Sul, Brasil

Vicente Gosciola I Universidade Anhembi Morumbi, Brasil

REVISÃO DE TEXTO E TRADUÇÃo I Everton Cardoso

EDITORAÇ̃̃o ELETRÔNICA I Raquel Castedo
COMPós I www.compos.org.br

Associação Nacional dos Programas de Pós-Graduação em Comunicação

Presidente

Erick Felinto de Oliveira

Universidade do Estado do Rio de Janeiro, Brasil erickfelinto@uol.com.br

Vice-presidente

Ana Silvia Lopes Davi Médola

Universidade Estadual Paulista, Brasil

asilvia@faac.unesp.br

Secretária-Geral

Denize Correa Araújo

Universidade Tuiuti do Paraná, Brasil

denizearaujo@hotmail.com 